\title{
Biosafety in Dental Practices Versus COVID-19 Outbreak
}

\author{
Ingrid Garcia Santos ${ }^{\circledR}$, Vívian Gonçalves Carvalho Souza ${ }^{\circledR}$, Guilherme Thomaz Verly da Silva1@, \\ Aneliese Holetz de Toledo Lourenço ${ }^{\mathfrak{D}}$, Laísa Araujo Cortines Laxe ${ }^{2,4}(\mathbb{D}$, Ana Carolina Morais \\ Apolônio $2,5(0)$
}

\begin{abstract}
${ }^{1}$ School of Dentistry, Federal University of Juiz de Fora, Juiz de Fora, MG, Brazil.
${ }^{2}$ Postgraduate Program in Dentistry, Federal University of Juiz de Fora, Juiz de Fora, MG, Brazil.

${ }^{3}$ Department of Dental Clinic, School of Dentistry, Federal University of Juiz de Fora, Juiz de Fora, MG, Brazil.

${ }^{4}$ Department of Restorative Dentistry, School of Dentistry, Federal University of Juiz de Fora, Juiz de Fora, MG, Brazil.

${ }^{5}$ Department of Parasitology, Microbiology, and Immunology, Institute of Biological Sciences, Federal University of Juiz de Fora, Juiz de Fora, MG, Brazil.
\end{abstract}

Correspondence: Ana Carolina Morais Apolônio, Universidade Federal de Juiz de Fora, Department of Parasitology, Microbiology, and Immunology, Institute of Biological Sciences, Juiz de Fora, MG, Brazil. 36036-900, E-mail: carolina.apolonio@ufjf.edu.br

Academic Editor: Alessandro Leite Cavalcanti

Received: 31 August 2020 / Review: 21 September 2020 / Accepted: 24 September 2020

How to cite: Santos IG, Souza VGC, Silva GTV, Lourenço AHT, Laxe LAC, Apolônio ACM. Biosafety in dental practices
versus COVID-19 outbreak. Pesqui Bras Odontopediatria Clín $\quad$ Integr.
https://doi.org/10.1590/pboci.2021.034

\begin{abstract}
Objective: To evaluate the dentists' knowledge about biosafety considering the SARS-CoV-2 and the risks of increasing the COVID-19 outbreak by dental practices during the pandemic in Brazil. Material and Methods: A cross-sectional study was performed by internet-based snowball sampling technique. A questionnaire with questions about different content was applied, and then analyzed the following two parameters: participants' Brazilian region and professional's specialty. Results: A total of 413 equestionnaires from all Brazilian regions were considered valid. There were no significant differences among biosafety measures adopted by participants from different Brazilian regions ( $\mathrm{p} \geq 0.05$ ), except for those from North region, which have applied less previous oral antisepsis, temperature screening, and specific anamnesis tracking COVID-19 symptoms $(\mathrm{p}<0.05)$. The unique use of N95 mask was positively associated with North region $(\mathrm{p}<0.05)$. Expert participants of Groups 2 (oral surgery and correlate areas) and 4 (orthodontics, oral radiology and facial jaw orthopedics) were more updated than other ones $(\mathrm{p}<0.05)$. Conclusion: The biosafety protocols applied by participants were not adequate for the epidemiologic status of COVID-19 in each region of Brazil, from 13th May to 17th June 2020. Specialties linked to microbiology area or structured social networks have better applied preventive measures for COVID-19.
\end{abstract}

Keywords: Infection Control, Dental; Personal Protective Equipment; Delivery of Health Care. 


\section{Introduction}

At the end of 2019, in Wuhan, China, was identified a novel disease caused by the SARS-CoV-2 (Severe Acute Respiratory Syndrome Coronavirus 2) and classified as COVID-19 (coronavirus disease of 2019) [1]. The most commonly reported routes of SARS-CoV-2 transmission include direct inhalation of aerosols or respiratory droplets from infected individuals and the indirect inhalation of virus-infected particles by touching contaminated surfaces [2]. Although symptomatic patients are the main transmission source, recent studies have shown the risk of transmission from asymptomatic patients and patients in their incubation period (from 2 to 12 days) [1,3]. Based on all these aspects, dental practices became imminent risks for the increase of the COVID-19 outbreak, mainly after SARS-CoV-2 has been detected in the saliva of infected patients [4].

Considering that the novel coronavirus can survive up to 3 hours in aerosol particles and stay viable up to 72 hours on plastic or stainless-steel surfaces, the aerosols produced from dental procedures offer a very high risk of cross-linked infection if hard control measures for biosafety are not followed by dental teams [5].

Recently, questions about dentistry's future were raised, facing little knowledge about SARS-CoV-2 pathogenesis [6]. Between March and June 2020, Brazil became the epicenter of the current coronavirus pandemic, being the worst outcome presented by the North region, followed by Northeast and Southeast [7].

Despite provisional guidelines published by the American Dental Association (ADA) highlighting the measures that must be observed by dentists, the confusion of much information from different sources during the pandemic has created doubts about the clinical routines by dental professionals. Considering the fundamental role of Dentistry as a healthcare area and the lack of standardized guides to readjust the dental practices, which allow biosafety for both dental team and patients, we hypothesized a high divergence of biosafety control measures among dentists during the current pandemic. Possibly, it could be powered by professionals' specialties and regions where they live.

Therefore, this study aimed to evaluate the dentists' knowledge about biosafety control measures to avoid the spread of SARS-CoV-2 and the risks of increasing the COVID-19 outbreak by dental practices during the coronavirus pandemic in Brazil.

\section{Material and Methods}

Study Design

A cross-sectional, qualitative-quantitative study was carried out using a self-administered online questionnaire through Google Forms platform (Alphabet Co., Mountain View, California, USA) with a convenience sample of active Brazilian dental professionals of both genders. The study was approved by the Research Ethics Committee - Federal University of Juiz de Fora (CEP/UFJF) - number 4.026.242.

Sample size was calculated considering the total number of dentists registered in the Federal Council of Dentistry (FCD) until April 2020 [8]. Confidence level of 95\%, margin of error of 5\% and distribution of $50 \%$ were applied. Then, sample size $=\left[\mathrm{z}^{2} \times \mathrm{p}(1-\mathrm{p}) / \mathrm{e}^{2}\right] / 1+\left[\mathrm{z}^{2} \times \mathrm{p}(1-\mathrm{p}) / \mathrm{e}^{2} \mathrm{~N}\right]$, being $\mathrm{N}=$ population size $(337,720)$; e = margin of error (0.05); $\mathrm{z}=\mathrm{z}$ value (1.96 for $95 \%$ confidence level); $\mathrm{p}=$ distribution of $50 \%(0.5)$. The sample size required was calculated as 384 participants. The sample included professionals aged $\geq 18$ years, registered in Regional Dentistry Council (CRD) of their states as dentists. Questionnaires partially completed were excluded.

Questionnaire Designs 
The questionnaire was developed with all authors' participation by individual review rounds and structured with 25 self-administered questions. The online questionnaire link was sent to professionals in all Brazilian states through digital platforms such as WhatsApp and Instagram (Facebook Inc., Menlo Park, California, USA), and e-mail. After reading the research presentation text and the Informed Consent Form, the participant should click on the "YES" option if he/she agreed to participate. Then, he/she was redirected to the questions.

Data Analysis

The data were transcripted to Microsoft Excel 2010 (Microsoft Corporation, Redmond, Washington, USA) and statistical analysis was performed using the Statistical Package for Social Science 21.0 (SPSS Inc., Chicago, USA). Descriptive analyses were performed with absolute and frequency measures. We also established an association between categorical variables using the Chi-square test with Monte-Carlo correction when necessary. The level of significance adopted was $5 \%(\mathrm{p}<0.05)$.

\section{Results}

A total of 474 e-questionnaires were obtained from 13th May to 17th June 2020, being that 34 participants had answered them more than once. Just the first one was considered. Hence, 39 e-questionnaires answered were disregarded. And, 22 e-questionnaires were not answered properly because they were incomplete. Then, they were removed too. Therefore, 413 valid answers were considered, representing 413 dentists legally registered in the council of dentistry from 26 Brazilian states and Federal District.

Most participants were female (69\%), 26-35 years old (40\%), and working up to 5 years $(40 \%)$ in private offices $(32 \%)$ or clinics $(31 \%)$. The specialties of the participants were grouped in 5 categories, according to the relationship between dental specialty and microbiology consciousness (Table 1). Within these groups, the number 1 was the most representative (49\%). All these data are shown in Table 1.

Table 1. Demographic data of the participants.

\begin{tabular}{|c|c|c|c|c|c|}
\hline \multirow{2}{*}{$\begin{array}{ll} & \text { Variables } \\
\text { Sex } & \end{array}$} & \multicolumn{5}{|c|}{ Participants N (\%) } \\
\hline & Male & Female & Rather not Answer & & \\
\hline & $127(30.75)$ & $285(69.01)$ & $1(0.24)$ & & \\
\hline \multirow[t]{2}{*}{ Age (in Years) } & $18-25$ years & 26-35 years & $36-45$ years & $46-55$ years & $56-75$ years \\
\hline & $64(15.50)$ & $166(40.19)$ & $108(26.15)$ & $42(10.17)$ & $33(7.99)$ \\
\hline \multirow[t]{2}{*}{ Groups of Dental Specialty } & Group 1 & Group 2 & Group 3 & Group 4 & Group 5 \\
\hline & $202(48.91)$ & $110(26.63)$ & $8(1.93)$ & $70(16.95)$ & $23(5.57)$ \\
\hline \multirow[t]{2}{*}{ Brazilian Regional Division } & Southeast & Northeast & South & Midwest & North \\
\hline & $219(53.03)$ & $97(23.49)$ & $9(2.18)$ & $21(5.08)$ & $67(16.22)$ \\
\hline \multirow[t]{2}{*}{ Work Condition } & $\begin{array}{c}\text { Individual Private } \\
\text { Practice }\end{array}$ & Private Clinic & $\begin{array}{l}\text { Private Practice with } \\
\text { Multiple Users }\end{array}$ & $\begin{array}{l}\text { Public } \\
\text { Settings }\end{array}$ & \\
\hline & $134(32.45)$ & $130(31.48)$ & $53(12.83)$ & $96(23.24)$ & \\
\hline \multirow[t]{2}{*}{ Years in Practice } & $0-5$ Years & 6-10 Years & 11-20 Years & 21-30 Years & $31-45$ Years \\
\hline & $165(39.95)$ & $63(15.25)$ & $100(24.22)$ & $48(11.63)$ & $37(0.06)$ \\
\hline Specialty Group by & Group 1 & Group 2 & Group 3 & Group 4 & Group 5 \\
\hline $\begin{array}{c}\text { Brazilian's Region } \\
\text { Southeast }\end{array}$ & $105(47.95)$ & $67(30.59)$ & $3(1.37)$ & $35(15.98)$ & $9(4.11)$ \\
\hline Northeast & $48(49.48)$ & $20(20.62)$ & $1(1.03)$ & $17(17.53)$ & $11(11.34)$ \\
\hline South & $2(22.22)$ & $2(22.22)$ & $1(11.11)$ & $3(33.33)$ & $1(11.11)$ \\
\hline MidWest & $5(23.81)$ & $9(42.86)$ & $3(14.29)$ & $3(14.29)$ & $1(4.76)$ \\
\hline North & $42(62.69)$ & $12(17.91)$ & $0(0.00)$ & $12(17.91)$ & $1(1.49)$ \\
\hline
\end{tabular}

Group 1: General Practice, Dentistry, Prosthetic Dentistry, Geriatrics Dentistry; Group 2: Oral Implantology, Periodontics, Oral Surgery, Endodontics; Group 3: Special Needs, Hospital Dentistry, Stomatology, Temporomandibular Pain; Group 4: Orthodontics, Oral Radiology, Facial Jaw Orthopedics; Group 5: Pediatric Dentistry, Public Health. 
The data obtained from 413 participants exceeded the sample size requested by the internet-based snowball sampling technique and also represented all five geographic Brazilian regions (Figure 1A). Considering the epidemiology of the COVID-19 during the period of this study [7] confirmed cases and deaths for COVID-19 [7] per 10.000 dentists ratios [8] (Figure 1B-C) were similar to our participants' ratio for the same unit (Figure 1) in Brazil.
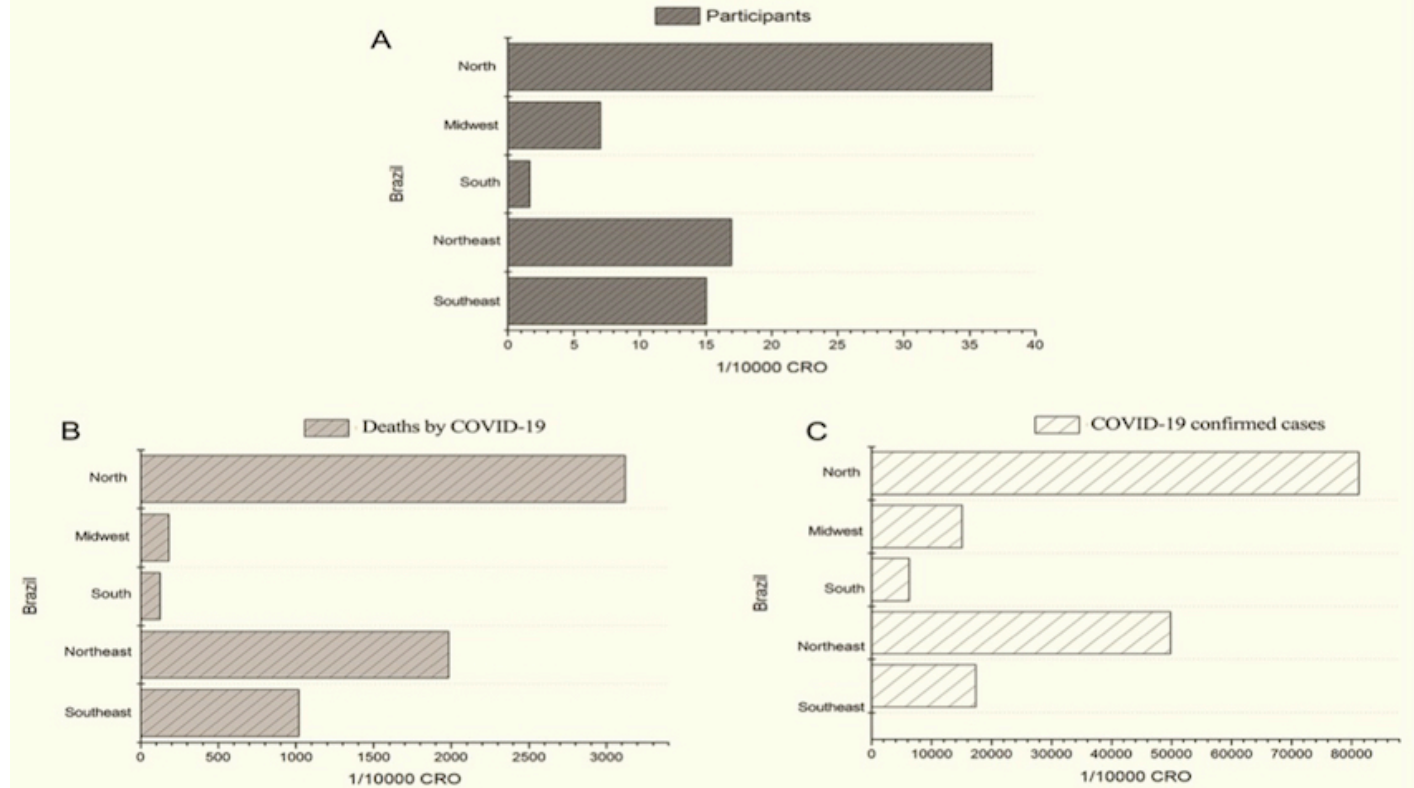

Figure 1 (A-C): Characterization of the study scenario considering the study participants (A), deaths for COVID-19 (B), and positive cases for COVID-19 (C) per 10.000 registered dentists among Brazilian regions.

To evaluate the data, the questionnaire items were divided into six groups of questions according to their content, following two parameters: Brazilian region where participants live and work, and dental professional's specialty.

Evaluation of Each Question According to Brazilian Regions

There were not significant statistical differences among Brazilian regions $(\mathrm{p}>0.05)$ for the first group of questions (Figure $2 \mathrm{~A}-\mathrm{G}$ ). However, it could be observed that sweat was wrongly cited as a transmission route by some participants (Figure $2 \mathrm{~A}$ ); a considerable part of the sample has not included specific questions about COVID-19 symptoms investigations in its anamnesis, especially in the North region (31\%; Figure 2B), and it has not worked with dental assistant (Figure $2 \mathrm{~F}$ ); and, readjustments in office waiting rooms and procedures after assisting a patient were similar among different regions in Brazil, but incorrect (Figure $2 \mathrm{E}, \mathrm{G}$ ).

There were no significant statistical differences among the Brazilian regions considering the conduct of dental professionals facing patients with suspects or positively tested for COVID-19, for both elective $(\mathrm{p}>0.05$; Figure 3A) and urgent appointments $(\mathrm{p}=0.05$; Figure $3 \mathrm{~B})$. Dentists from North region have applied less previous antisepsis than from other Brazilian regions (Figure 3C; $<<0.05$ ). However, the choices for procedures or equipments that generate little or no aerosol were not associated with the different regions (Figure 3D; $>0.05$ ). Within the questions evaluating how professionals have conducted their dental assistance during the COVID-19 pandemic, the North region has demonstrated the worst scenario for temperature 
screening (Figure 3E; p<0.05) and specific anamnesis tracking any symptom of respiratory infection (Figure $3 \mathrm{~F} ; \mathrm{p}<0.05)$. Guidelines performed for patients when they arrive at dental offices are different all over Brazil $(\mathrm{p}<0.05$; Figure $3 \mathrm{G})$. Within the answers, options for guidelines related to patients' care before the dental appointments, do not take a company, wear a mask, and cancel the appointment if symptomatic were cited correctly, but divergence in choices was associated with the region $(\mathrm{p}<0.05$; Figure $3 \mathrm{H})$. In this case, South region presented the worst scenario.

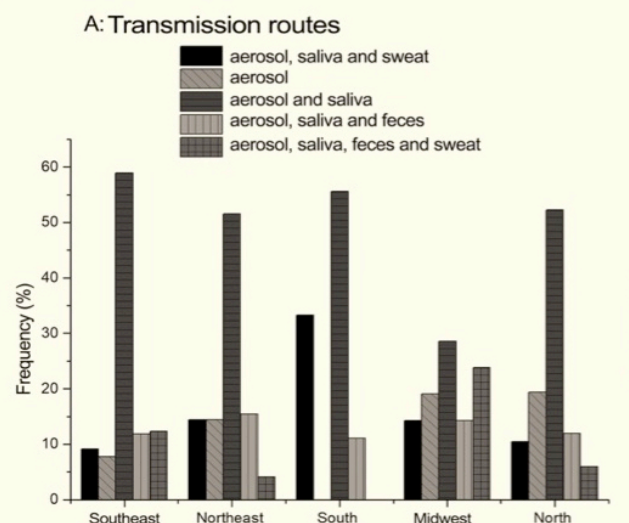

C: Office precautions to receive patients

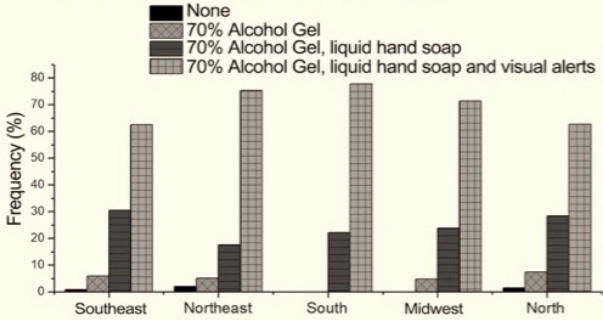

E: Waiting room care

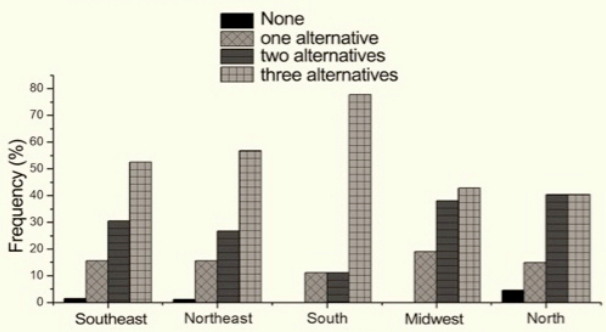

G: Handling instruments after dental assistances

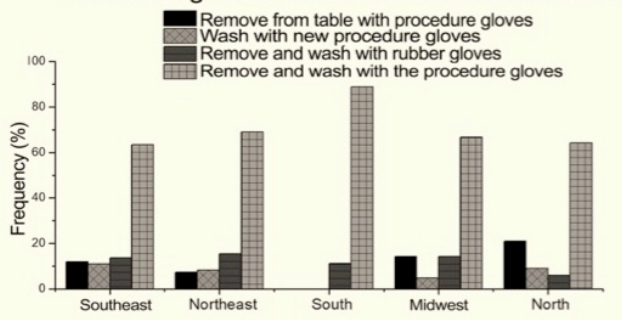

B: Questions about COVID-19 symptoms

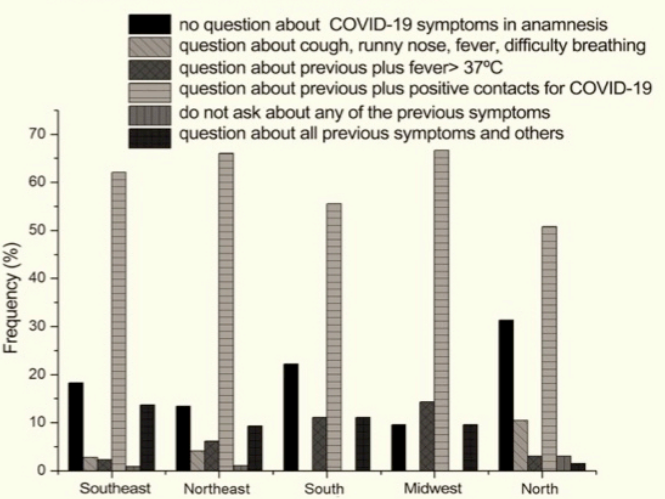

D: Placement of mechanical barriers

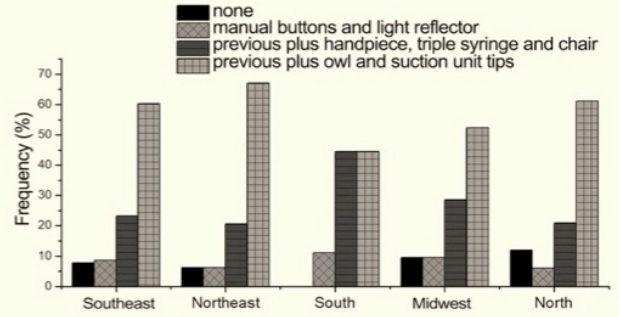

F: Guidelines for the assistant

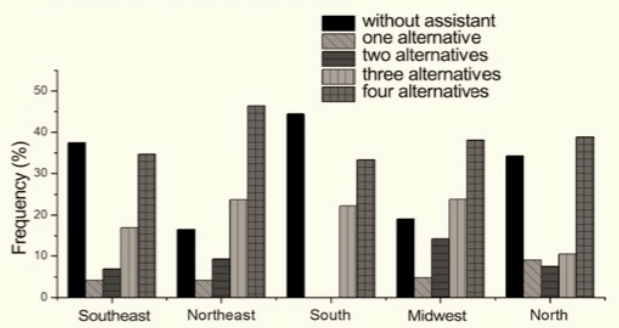

$\mathrm{H}$ : Chemical agents to disinfect surfaces

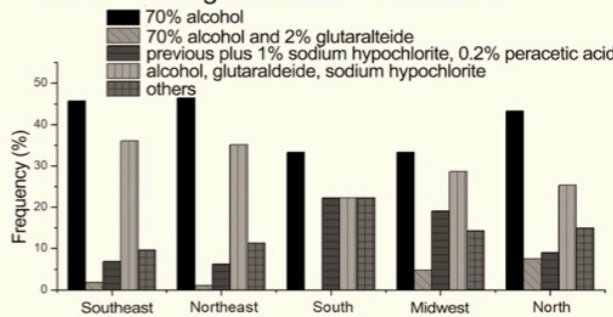

Figure 2 (A-H): There were no significant statistical differences among Brazilian regions $(\mathrm{p}>0.05)$ for the following questions: knowledge about Sars-CoV-2 transmission routes (A); use of specific questions about COVID-19 symptoms during anamnesis (B); use of $70 \%$ alcohol gel, liquid hand soap, and visual alerts as precautions for receiving patients (C); placement of mechanical barriers (D); adequacy performed in office waiting room considering the alternatives: none, magazines and handling artifacts removed, schedule distant times between patients and office cleanliness at each patient change (E); presence of assistants in dental teams and guidelines for them (F); use of gloves to remove and wash instruments after patient assistance $(G)$; and, use of $70 \%$ alcohol solution as a first chemical agent to disinfect surfaces $(H)$. 

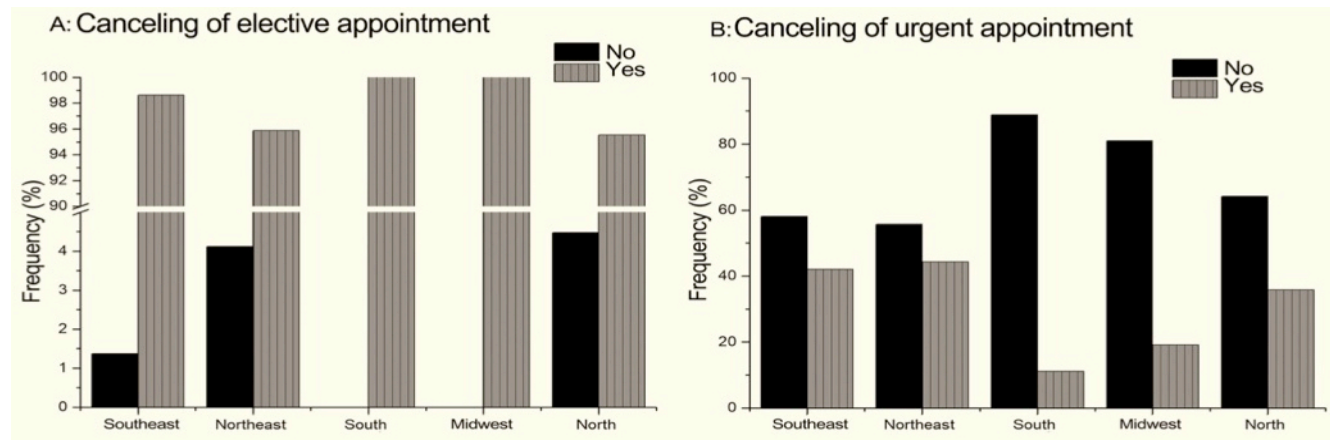

C: Previous oral antisepsis

D:Clinical readjustments during dental assistances
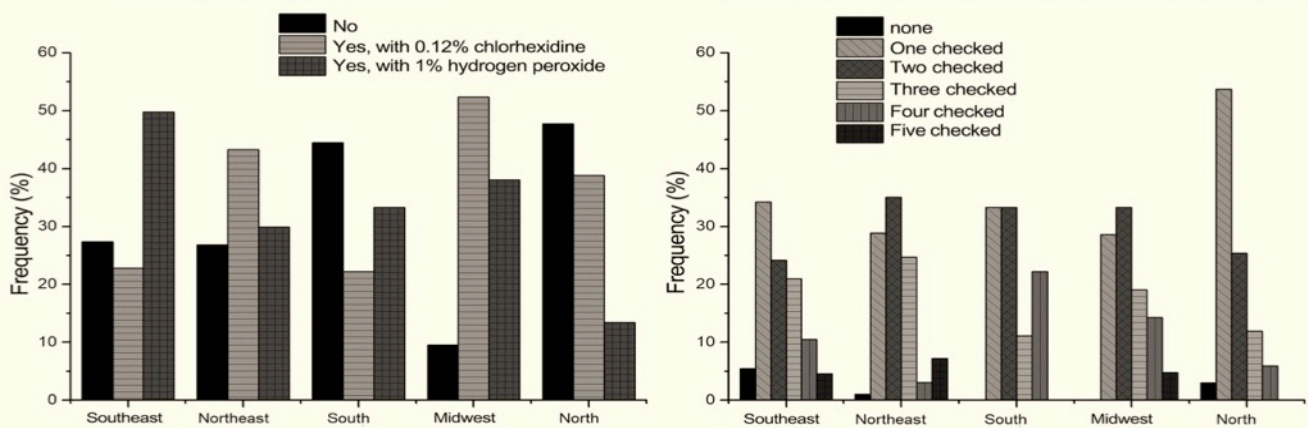

E: Temperature screening before assistance

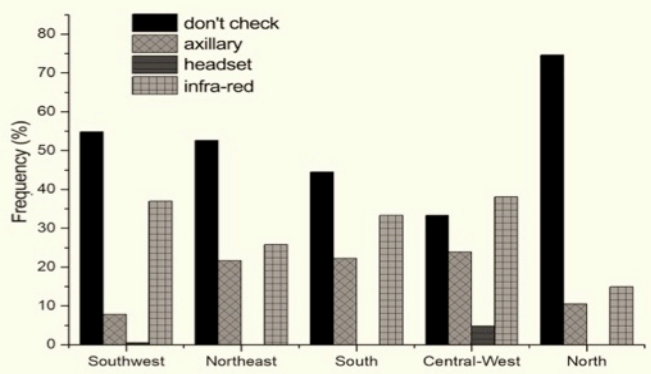

F: Specific anamnesis to track history of possible COVID-19 symptoms

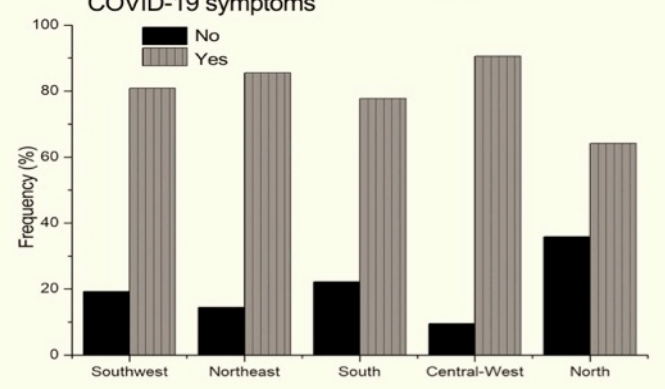

G: Guidelines for patients in dental office
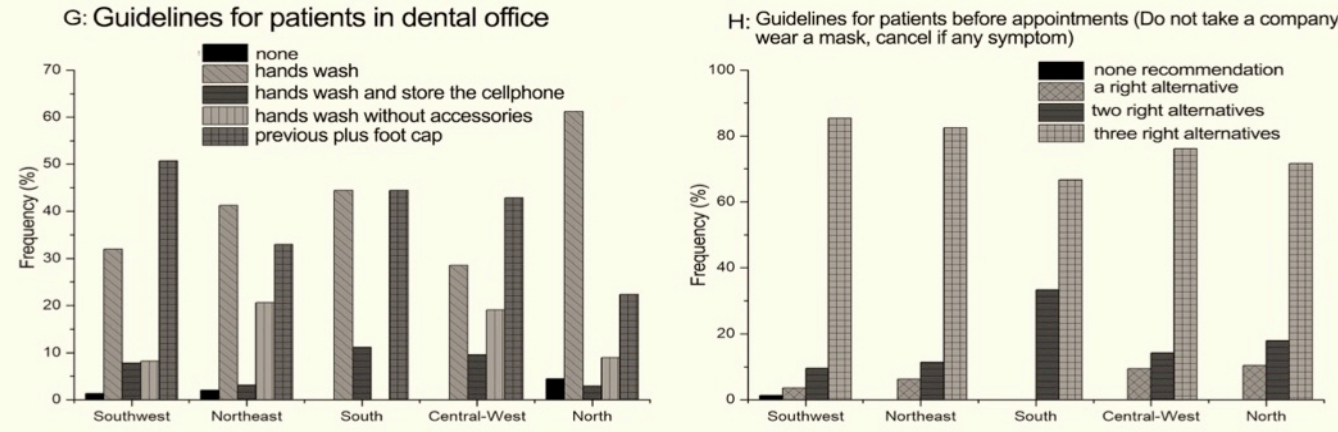

Figure 3 (A-H): Dental professionals' conduct related to patients with suspect or positively tested for COVID-19, considering elective $(A ; p>0.05)$ and urgent $(B ; p=0.05)$ appointments. Antisepsis was not performed equally all over Brazil $(\mathrm{C} ; \mathrm{p}<\mathbf{0 . 0 5})$. Clinical adaptations as use of turbine without water spray or in low speed, hand instruments, rubber dam, and others were not associated to Brazilian regions (D; p>0.05). The temperature screening (E), specific anamnesis to track history of possible COVID-19 symptoms $(F)$, guidelines for patients $(G)$, and choice divergences for patient care before appointments $(\mathrm{H})$ were associated to different Brazilian regions $(\mathbf{p}<0.05)$.

Within the questions applied to investigate the use of masks (Figure 4), most participants have used N95 masks for any procedure and it was not associated with any Brazilian regions (Figure 4A). However, the N95 unique use was associated to North region (Figure 4B; $<<0.05$ ). The frequency of participants that have not used N95 masks was $8.2 \%$ in Southeast, 2.7\% in Northeast, $1 \%$ in Midwest, and 3.9\% in the North region. All participants from South region have used N95 masks. However, just the use of N95 is not enough. It must 
adequately seal the professionals' faces and be removed from outside the dental procedures room, mainly when aerosols have been spread from clinical procedures. Although the participants from different Brazilian regions have answered similarly for both questions (Figure 4C-D), some participants are already making it wrong.

Although many participants have used face shield, the lack of this one was more associated to North region (Figure 4E). Finally, most participants have performed the correct sequence to remove PPEs (gloves face shield - coat - cap - mask), but a high parcel of them has made it in an inadequate way (Figure $4 \mathrm{~F}$ ).

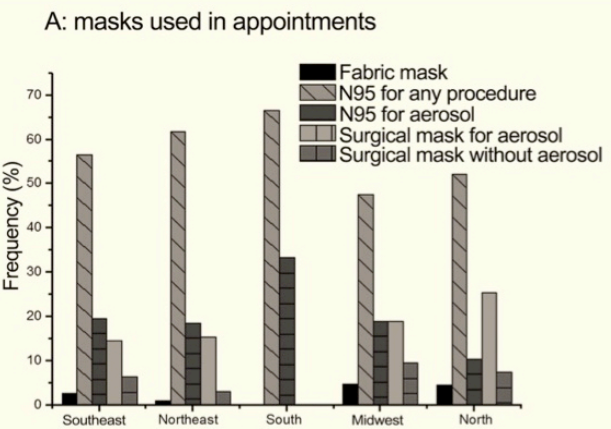

C: Influence of beard and makeup on N95 sealing

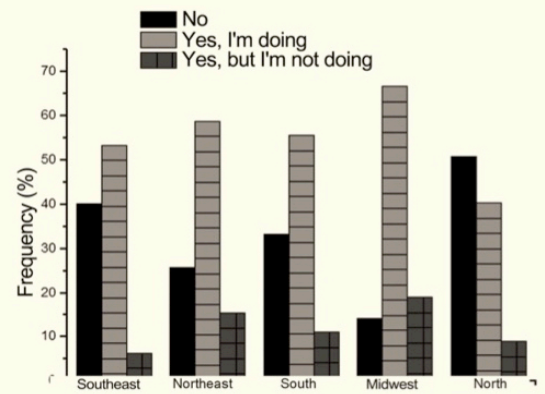

E: Using face shields

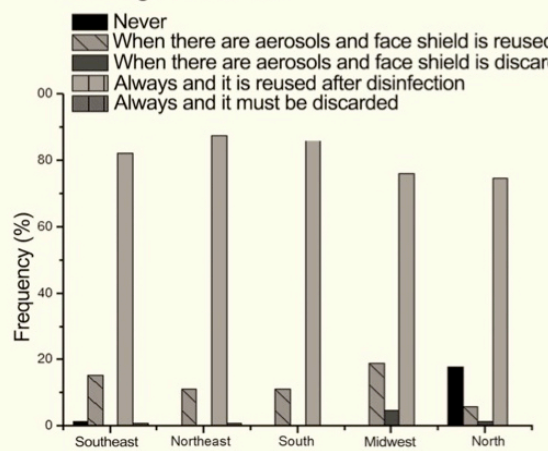

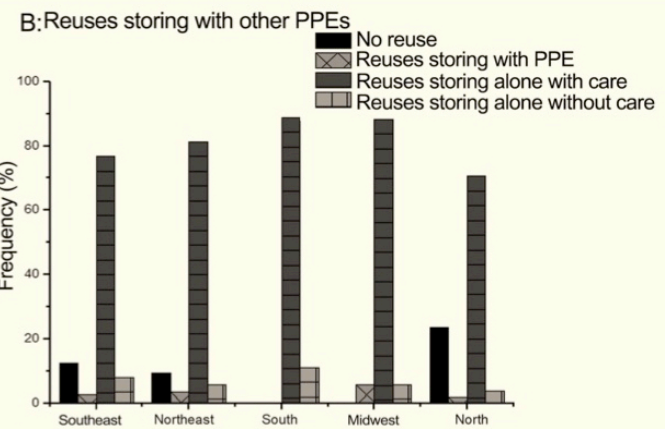

D: When remove the mask?

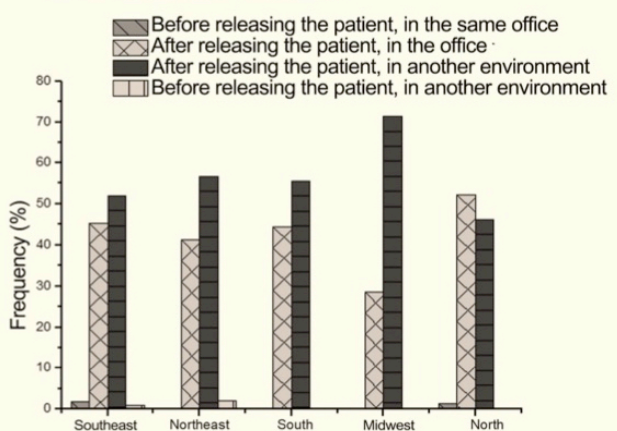

F: Sequence to remove PPE

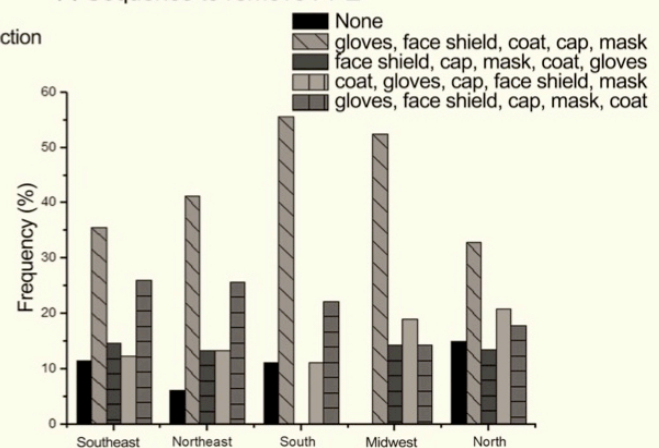

Figure 4 (A-F): The kind of mask used in appointments by dental professionals was not associated to Brazilian region (A; p>0.05). Reuse times of N95 (B). Factors that can damage the N95 sealing (C), and the moment which professionals remove their masks (D) were similar among Brazilian regions $(p>0.05)$. The no utilization of face shield was associated to North region $(E ; p<0.05)$. The sequence applied to remove all PPEs were similar among Brazilian regions $(\mathrm{F} ; \mathrm{p}>0.05)$.

Evaluation of Some Questions According to Professional Specialty Groups

The distribution of participants' specialties, according to the Brazilian region, is presented in Table 1. Some relationships between biosafety questions and dental specialties could be observed (Figure 5). While group 1 has made less oral antisepsis than others, the greatest use of hydrogen peroxide previously to dental procedures has been demonstrated by participants of group 2 , followed by group 4 (Figure $5 \mathrm{~A} ; \mathrm{p}<0.05)$. The 
clinical readjustments of procedures and equipments to avoid spread aerosols also have been different among the groups (Figure $5 \mathrm{~B} ; \mathrm{p}<0.05$ ).

A: Performs oral antisepsis on the patient

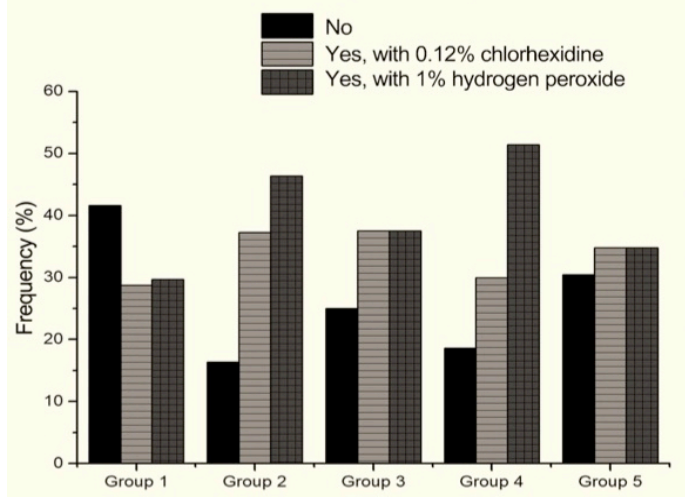

C: masks used in appointments

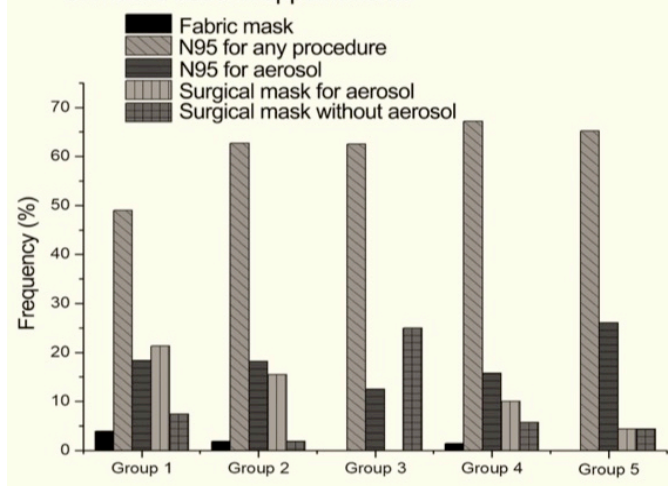

$\mathrm{E}:$ When remove the mask?

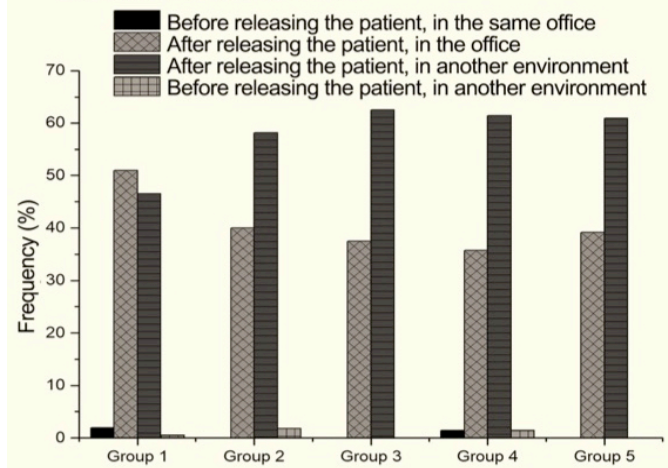

B: Number of clinical adaptations during service

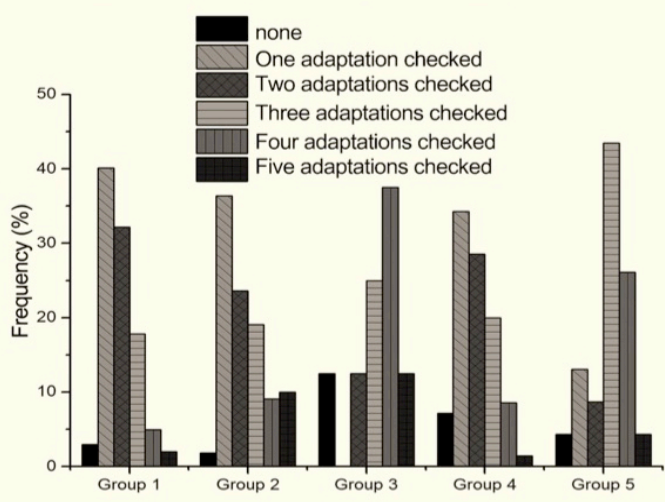

D:Reuses storing with other PPEs

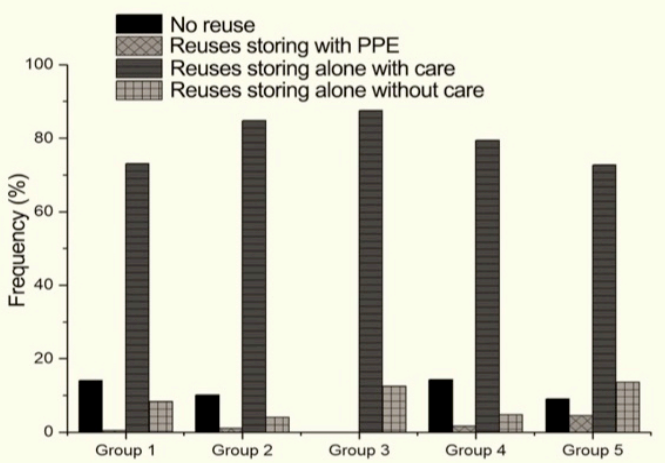

F: Influence of beard and makeup on N95 sealing

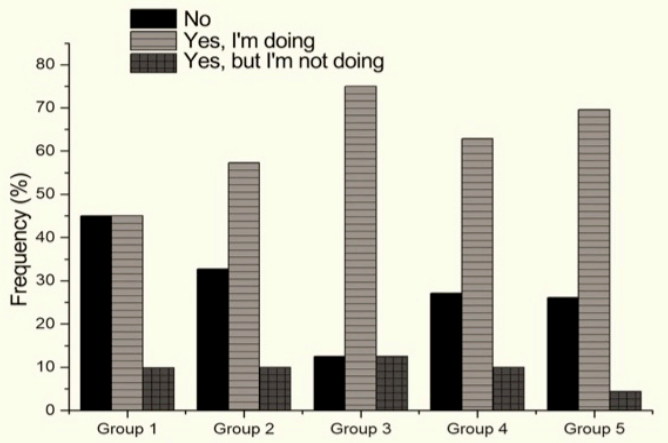

Figure 5 (A-F): There was an association between the groups of dental specialties and oral antisepsis performed (A; $\mathbf{p}<0.05)$. Clinical adaptations to avoid spread aerosols $(B)$ and the kind of mask used in appointments $(C)$ were associated to groups of dental specialties $(p<0.05)$. Reuse times of N95 was not associated to groups $(\mathrm{D} ; \mathrm{p}>\mathbf{0 . 0 5})$. The moment of removing the mask was most improperly associated to group $1(\mathrm{E} ; \mathrm{p}<0.05)$. Knowledge and action of shave and makeup on the N95 sealing were more associated to group $3(\mathrm{~F} ; \mathrm{p}<0.05)$.

The participants of groups 2 and 4 were more updated than other ones regarding the use of N95 mask for any dental clinic procedure (Figure $5 \mathrm{C} ; \mathrm{p}<0.05)$. However, its way of use was not associated to dental specialties (Figure 5D; p>0.05). The frequency of participants that have not used the N95 mask was $11.1 \%$ for group 1, 2.7\% for group 2, 1.7\% for group 4, and 0.2\% for group 5. All participants of group 3 have used N95. Although most participants of group 1 have removed the N95 adequately, a considerable part of them do it inappropriately (Figure 5E; $<<0.05$ ). Finally, the most participants seemed to have been informed that beard 
and makeup can damage the N95 sealing on their faces because the participants of group 3 showed a better knowledge and action related to these aspects (Figure $5 \mathrm{~F} ; \mathrm{p}<0.05)$.

\section{Discussion}

The public health emergency from COVID-19 brought up the risks of infection from dental practices due to aerosols' large release by dental procedures [1]. Within the routes of spreading harmful microorganisms, saliva-droplet through aerosol released by an infected patient, direct contact with contaminated surfaces, and water droplet aerosol emitted from contaminated unit reservoirs of handpieces dental equipment should be considered to infection control measures in the current situation and future $[1,9,10]$.

Our study joined opinions of different groups of dentists, considering the Brazilian region where they work. Expressive rates of participants living in Brazilian regions with the worst outcomes of COVID-19 during the research period were obtained. Moreover, the participant rates as the number of deaths and confirmed cases for COVID-19 per 10.000 Brazilian dentists were highest in the North region, followed by Northeast and Southeast regions [7]. Although this study originated in the Southeast Brazilian region, the considerable sample from the North and Northeast regions was the main contributing factor for the sample representativeness in this study.

The information via legacy media, as television and newspaper, about the regions most affected by the COVID-19 outbreak, could have led dental professionals in these same regions to search for protective behaviors in face of their risks of vulnerability [11]. Hence, we could speculate that it encouraged an expressive number of dentists in the North, Northeast, and Southeast of Brazil to participate in this study and contribute by the appointment of best control measures to contain the spreading of SARS-CoV-2 by dental assistances.

The lack of leaders to recommend coordinated measures to control the coronavirus pandemic in the national scenario has deviated more attention of dental professionals for technical aspects related to biosafety, such as the use of PPEs, pre-operative mouthwashes, and disinfectant solutions, than for basic readjustments to receive patients and to control the transit of people in dental offices during the COVID-19 pandemic as suggested by different sanitary agencies [12]. Topics related to knowledge about SARS-CoV-2 transmission routes, use of $70 \%$ alcohol for surface disinfection, use of liquid hand soap or $70 \%$ alcohol for hands disinfection, the assistance of just dental urgent cases, choice of dental procedures that generate little or none aerosol, and the use of N95 masks were not associated to different Brazilian regions. However, some of them have demonstrated many questionable behaviors by dentists all over Brazil.

Although most participants have cited sweating as a risk of the novel coronavirus transmission, it is not true, instead the feces [13]. It should emphasize the importance of frequent and appropriate hand hygiene and the risks to share bathrooms with other people. Although Propper [14] has raised doubt if the sweat could be considered a route for coronavirus transmission, no scientific data supports this relationship.

Considering the guidance documents published by some sanitary agencies, $70 \%$ alcohol solutions to disinfect surfaces could be replaced by other low-cost disinfectant solutions that are also effective against SARS-CoV-2, such as sodium hypochlorite solution [15]. The N95 mask has been considered an important PPE and its wide use by healthcare professionals has been usually the theme of news in legacy media. The lack of adequate PPEs worldwide allowed the WHO to indicate the reusing of the N95 mask by healthcare professionals since the storage conditions are appropriated. However, the gold pattern for biosafety is already 
using the N95 mask once [16-18]. Although participants have related-use N95 masks for any dental procedure, many of them have taken out the mask in the same room where dental operative procedures are performed and often using makeup or beard on their faces, reducing the sealing of the N95 [12].

Other topics related to the assistance of dental urgent cases of suspected or confirmed for COVID-19 patients, and the lack of temperature screening when patients arrive in dental offices, specific anamnesis tracking any respiratory involvement symptom in the last 14 days, antisepsis previously dental procedures, and face shield have been more associated with worst outcomes for the North region, following the same scenario for the COVID-19 pandemic in this Brazilian region. Until 17th June 2020, some sanitary agencies recommended patient triage by telephone, including specific questions about symptoms for COVID-19, and temperature screening in reception as important steps to avoid the SARS-CoV-2 transmission by dental practices $[12,16,17]$. These previous protocols can detect suspect symptoms and break complete- or partially the virus transmission route since the patient left his/her home, representing an important control of contaminated people for public health care [16,17].

Pre-operative mouthwashes can also reduce the viable viral load in the oral environment [19].Hence this antisepsis would contribute to minimizing the imminent risk from aerosol released in the air of the dental operative procedure room, ensuring more safety for dental teams. During the period that participants of this research were answering the e-questionnaires, protocols were indicating pre-operative mouthwashes with $0.12 \%$ chlorhexidine, followed by $1 \%$ hydrogen peroxide solutions. However, current protocols indicate the use of $0.12 \%$ chlorhexidine only [20,21].

Although Brazilian dentists have an important position in the international dentistry scenario, standardized protocols for acquiring and maintaining biosafety for dental practices were not relevant until the current pandemic [22]. However, COVID-19 disease brought a new paradigm for biosafety in dental offices. The results of this study could reinforce the importance of applying knowledge from basic sciences to clinical practices of different dental specialties.

Microbiology is an important basic science for public health care. It is widely linked to the work of dental professionals, as related to oral microbiota involved in several specific or systemic pathologies as to control measures for biosafety maintenance during dental assistance. Dentists usually know and apply control measures to prevent transmission of blood-borne viruses, as hepatitis B and C, HIV, and cross-linked infection by opportunist microorganisms [9].

According to their specialties, we can highlight the second group of participants in this study, which included Oral Implantology, Periodontics, Surgery, and Endodontics. Their answers showed the best microbiologic consciousness about biosafety measures to prevent transmission of SARS-CoV-2 during dental assistance, followed by group 4, which presented orthodontics, oral radiologists, and facial jaws orthopedics. These specialties (group 4) usually emit little or no aerosol during their clinical procedures. Hence, our results surprised the researchers of this study. Eventually, social contact networks well organized and structured, which brings together many orthodontists and radiologists in Brazil for exchange information, such as "Ortodontia Brasil", might be contributing to share new biosafety protocols since the start of the coronavirus pandemic in Brazil [11].

Based on all the latest results presented, the main knowledge about SARS-CoV-2 transmission and pathogenesis demonstrated by participants of this research seemed to be very similar to published by legacy media ones. It becomes easier to look at how the legacy of widespread media could be an important channel to disseminate news from recent researches, especially during an emergency scenario of public health [11]. Even 
when the information originally seems to be directed for a restricted group, after its spreading, it would impact all the society positively, leading to reach solutions, create new protocols, develop new strategies more quickly. The widespread media should go along with science.

Therefore, this research suggested that the standardized guidance documents for biosafety were not accessible for all dental professionals, considering the nature of their work activities among different regions in Brazil and different dentistry specialties. This context difficult the setting of similar biosafety measures to control the spread of the COVID-19 pandemic by this specific and important group of healthcare professionals, which must also work to educate, prevent, and promote public health.

\section{Conclusion}

The biosafety protocols applied by dental professionals were not adequate for the epidemiologic status of COVID-19 in each region of Brazil, from 13th May to 17th June 2020. Furthermore, the findings reinforce the importance of applying knowledge from basic sciences, especially microbiology, to clinical practices of different dental specialties. Moreover, specialties with organized and structured social networks are more conscious about biosafety measures to prevent the transmission.

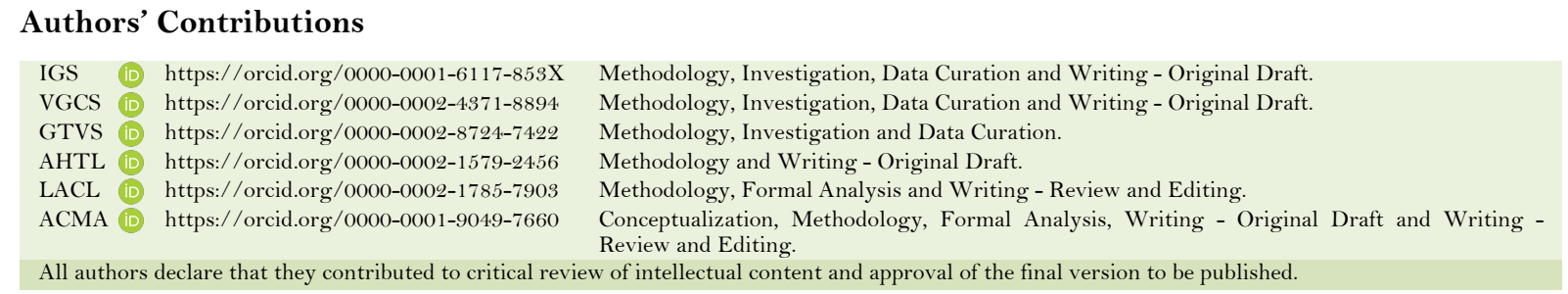

\section{Financial Support}

This study was financed in part by the Coordenação de Aperfeiçoamento de Pessoal de Nível Superior - Brasil (CAPES) - Finance Code OO1.

\section{Conflict of Interest}

The authors declare no conflicts of interest.

\section{Data Availability}

The data used to support the findings of this study can be made available upon request to the corresponding author.

\section{Acknowledgments}

Federal University of Juiz de Fora.

\section{References}

[1] Meng L, Hua F, Bian Z. Coronavirus disease 2019 (COVID-19): emerging and future challenges for dental and oral medicine. J Dent Res 2020; 99(5):481-7. https://doi.org/10.1177/0022034520914246

[2] Jamal M, Shah M, Almarzooqi SH, Aber H, Khawaja S, El Abed R, et al. Overview of transnational recommendations for COVID-19 transmission control in dental care settings. Oral Dis 2020. https://doi.org/10.1111/odi.13431

[3] Lai CC, Shih TP, Ko WC, Tang HJ, Hsueh PR. Severe acute respiratory syndrome coronavirus 2 (SARS-CoV-2) and coronavirus disease-2019 (COVID-19): the epidemic and the challenges. Int J Antimicrob Agents 2020; 55(3):105924. https://doi.org/10.1016/j.ijantimicag.2020.105924

[4] To KKW, Tsang OTY, Leung WS, Tam AR, Wu TC, Lung DC, et al. Temporal profiles of viral load in posterior oropharyngeal saliva samples and serum antibody responses during infection by SARS-CoV-2: an observational cohort study. Lancet Infect Dis 2020; 20(5):565-74. https://doi.org/10.1016/S1473-3099(20)30196-1 
[5] van Doremalen N, Bushmaker T, Morris DH, Holbrook MG, Gamble A, Williamson BN, et al. Aerosol and surface stability of SARS-CoV-2 as compared with SARS-CoV-1. N Engl J Med 2020; 382(16):1564-7. https://doi.org/10.1056/NEJMc2004973

[6] Hua CG, Liu ZQ, Wang Q, Yang Z, Xu QH, Zhang J. Strategy of dental clinics to cope with the epidemic period of infectious diseases based on the experience of corona virus disease outbreak. Hua Xi Kou Qiang Yi Xue Za Zhi 2020; 38(2):117-2 1. https://doi.org/10.7518/hxkq.2020.02.001

[7] Ministério da Saúde. Boletim Epidemiológico Especial. Doença pelo Coronavírus COVID-19. Semana Epidemiológica 25; 2020. Available from: http://saude.gov.br/images/pdf/2020/June/25/Boletim-epidemiologico-COVID-19-2.pdf [Accessed on June 19, 2020]. [In Portuguese]

[8] Conselho Federal de Odontologia. Quantidade geral de profissionais e entidades ativas; 2020. Available from: http://website.cfo.org.br/estatisticas/quantidade-geral-de-entidades-e-profissionaisativos/?doing_wp_cron= 1593018748.1152129173278808593750 [Accessed on June 19, 2020]. [In Portuguese]

[9] Szymanska J. Microbiological risk factors in dentistry. Current status of knowledge. Ann Agric Environ Med 2005; 12(2):157-63.

[10] Volgenant CMC, Persoon IF, Ruijter RAG, de Soet JJH. Infection control in dental health care during and after the SARS-CoV-2 outbreak. Oral Dis 2020. https://doi.org/10.1111/odi.13408

[11] Chan MS, Winneg K, Hawkins L, Farhadloo M, Jamieson KH, Albarracín D. Legacy and social media respectively influence risk perceptions and protective behaviors during emerging health threats: a multi-wave analysis of communications on Zika virus cases. Social Sci Med 2018; 212:50-9. https://doi.org/10.1016/j.socscimed.2018.07.007

[12] Cochrane Oral Health. London: Recommendations for the re-opening of dental services: a rapid review of international sources; 2020. Available from: https://oralhealth.cochrane.org/news/recommendations-re-openingdental-services-rapid-review-international-sources [Accessed on June 25, 2020].

[13] Wang W, Xu Y, Gao R, Lu R, Han K, Wu G, et al. Detection of SARS-CoV-2 in different types of clinical specimens. JAMA 2020; 323(18):1843-4. https://doi.org/10.1001/jama.2020.3786

[14] Propper RE. Is sweat a possible route of transmission of SARS-CoV-2? Exp Biol Med 2020; 245(12):997-8. https://doi.org/10.1177/1535370220935409

[15] United States Environmental Protection Agency. Washington: List N: Disinfectants for Use Against SARS-CoV-2 (COVID-19); 2020. Available from: https://www.epa.gov/pesticide-registration/list-n-disinfectants-use-against-sarscov-2-covid-19 [Accessed on June 25, 2020].

[16] American Dental Association. What constitutes a dental emergency?; Available from: https://success.ada.org/ /media/CPS/Files/Open\%20Files/ADA_COVID19_Dental_Emergency_DDS.pdf?utm_s ource=adaorg\&utm_medium $=$ covidresources-lp\&utm_content $=$ cv-pmemergdef\&utm_campaign $=$ covid $19 \& \_g a=$ 2.158719422.527261862.1584796909-1982106663.1584563184. [Accessed on June 25, 2020].

[17] Centers for Disease Control and Prevention. Guidance for Dental Settings. Available from: https://www.cdc.gov/coronavirus/2019-ncov/hcp/dental-settings.html. [Accessed on June 25, 2020].

[18] Tirupathi R, Bharathidasan K, Palabindala V, Salim SA, Al-Tawfiq JA. Comprehensive review of mask utility and challenges during the COVID-19 pandemic. Infez Med 2020; 28(Suppl 1):57-63.

[19] Yengopal V, Mickenautsch S. Chlorhexidine for the prevention of alveolar osteitis. Int J Oral Maxillofac Surg 2012; 41(10):1253-64. https://doi.org/10.1016/j.ijom.2012.04.017

[20] Yoon JG, Yoon J, Song JY, Yoon S-Y, Lim CS, Seong H, et al. Clinical significance of a high SARS-CoV-2 viral load in the saliva. J Korean Med Sci 2020; 35(20):e195. https://doi.org/10.3346/jkms.2020.35.e195

[21] Ortega KL, Rodrigues de Camargo A, Franco JB, Azul AM, Sayáns MP, Braz Silva PH. SARS-CoV-2 and dentistry. Clin Oral Invest 2020; 24(7):2541-2. https://doi.org/10.1007/s00784-020-03381-7

[22] Askarian M, Mirzaei K, Honarvar B, Etminan M, Araujo MWB. Knowledge, attitude and practice towards droplet and airborne isolation precautions among dental health care professionals in Shiraz, Iran. J Public Health Dent 2005; 65(1):43-7. https://doi.org/10.1111/j.1752-7325.2005.tb02785.x 